Europe's Journal of Psychology 1/2010, pp. 63-81

www.ejop.org

\title{
Burnout, work satisfactions and psychological well-being among nurses in Turkish hospitals
}

Ronald J. Burke

York University

Mustafa Koyuncu

Nevsehir University

Lisa Fiksenbaum

York University

\section{Abstract}

This exploratory study examined the relationship between self-reports of burnout and indicators of work satisfaction and engagement, perceptions of hospital functioning and quality of nursing care, and psychological well-being of nursing staff. Data were collected from 224 staff nurses using anonymously completed questionnaires, a 37 percent response rate. Three indicators of burnout were considered: emotional exhaustion, cynicism, and lack of personal efficacy. Hierarchical regression analyses, controlling for both personal demographic and work situation characteristics, indicated that burnout accounted for significant increments in explained variance on most outcome measures. Explanations for the association of burnout with various outcomes are offered along with potentially practical implications.

\section{Background}

Nurses occupy a central role in the delivery of health care in all countries, though countries may have different health care systems and methods of payment options. Unfortunately studies of the work experiences and satisfactions of nurses in several countries indicate that the satisfaction of nurses is modest. Many report negative attitudes and diminished psychological and physical well-being, and several would like to leave the profession. (Aiken, Clarke, Sloane \& Sochalski, 2001) In addition, nursing as a profession is now less attractive for young women and men than it was 
earlier. Some countries are now reporting a shortage of nurses, often compounded by the fact that richer nations are luring nurses away from poorer ones. The health care system has also undergone significant change over the past decade. These stem from the greater use of new technologies, off-shoring some services to developing countries, advances in medical knowledge, an aging population, more informed and critical users of the health care system, and efforts by governments to further control health care expenditures.

It is not surprising then that considerable research has been undertaken in several countries to understand the work experiences of nurses, particularly as they relate to nurse satisfaction and well-being and patient care. It has concentrated on issues of workload, lack of resources, overtime work, and increases in abuse experienced in the work place by nursing staff as these affect burnout, depression, psychosomatic symptoms, absenteeism and intent to leave the profession. The bulk of nursing research has used a stressor-strain framework and has contributed a great deal to our understanding of the experiences of nurses in their workplaces.

Recent research has increasingly considered burnout as an important workplace strain found to be associated with adverse psychological and physical health of employees and lower levels of job performance. Although burnout was first identified among women and men working in the helping professions, recent studies have considered burnout to be relevant to any profession. Burnout is a psychological syndrome that develops in response to chronic work related stressors (Maslach, Schaufeli \& Leiter, 2001). Maslach and Jackson $(1981,1996)$ defined burnout as a syndrome of emotional exhaustion, a cynical attitude towards work, and lack of personal accomplishment. Burnout is associated with negative health consequences for individuals, and with diminished work performance in organizations (Maslach \& Leiter, 1997; Schaufeli, Maslach \& Marek, 1993).

Burnout among nurses has received considerable research attention (see Poncet, Toullic, Papazian, Kentish-Barnes, Timsit, Pochard, Chevret, Schlemmer and Azoulay, 2007; Bakker, LeBlanc, \& Schaufeli, 2005; Chen \& McMurray, 2001; Leiter \& Maslach, 2009; Papadatou, Anagnostopoulos \& Monos, 1994). Nursing is as profession that requires investing considerable time and energy in relationships with others seeking treatment and care, often in trying circumstances. Burnout is likely to be heightened in these potentially intense and demanding relationships. The nursing environment also has elements likely to increase feelings of burnout including heavy workloads, lack of resources, lack of respect from doctors, and little input into unit decision making. 
Aiken, Clarke, Sloane, Sochalski and Silber (2002), in a large sample of both nurses and patients in he US, found that for each additional patient per nurse levels of patient mortality and levels of nurse burnout and job dissatisfaction increased. Greenglass, Burke and Fiksenbaum (2001) reported that quantitative workload was associated with higher levels of burnout which in turn increased psychological symptoms in the same Canadian nursing sample. Vahey, Aiken Sloane, Clarke and Vargas (2004), in a large sample of both nurses and patients from 40 nursing units in 20 urban hospitals in the US, found that patients cared for on units that nurses described ad having adequate staff, good administrative support for nursing care, and good relations between doctors and nurse, were more than twice as likely as other patients to report high satisfaction with their care, and their nurses reported significantly lower burnout. In addition nurse burnout was associated with lower patient satisfaction. Laschinger, Finegan, Shamian and Wilk (2003), in a longitudinal study of Canadian nurses, found that nurses feeling empowered in their workplaces (e.g., had access to information, support, resources and opportunity to learn and develop) also indicated significantly lower levels of burnout. Finally, Bakker, Killmer, Seigrist and Schaufeli (2000) reported that higher levels of nursing burnout were associated with greater effort-reward imbalance.

The initial research on antecedents and consequences of burnout began in the late 1970s in the US but now extends to almost every country in the world. In fact burnout has now become a medical diagnosis in some countries (Schaufeli, Leiter \& Maslach, 2008) highlighting the significance of the concept.

The present exploratory study considers the relationships of measures of nurses' burnout and a variety of work satisfaction, psychological well-being and perceptions of quality of nursing care among nurses working in Turkish hospitals. Burnout was measured by the Maslach Burnout Inventory (MBI), the most widely used measure of burnout. Burnout is typically seen as a multi-dimensional construct (Maslach, Leiter \& Schaufeli, 2009) and the $\mathrm{MBI}$ assesses three components. No other research on work experiences of nurses in Turkey, to our knowledge, has considered these issues This research then makes two important contributions. First it examines burnout among nurses working in Turkish hospitals. No other research on work experiences of nurses in Turkey, to our knowledge, has considered these issues. Second, it adds novel outcomes measures germane to the nursing context (e.g., health and safety perceptions, errors and accidents).

Three categories of outcome variables were included in the study: work outcomes, indicators of psychological well-being, and aspects of hospital functioning. Various writers and researchers have examined the relationship of burnout with variables in 
these categories or have reviewed this literature (e.g., Burke \& Richardsen, 2001; Leiter \& Maslach, 2005; Schaufeli \& Buunk, 2003; Schaufeli, Leiter \& Maslach, 2008: Shirom \& Melamed, 2005).These reviews support the following conclusions about the relationship of burnout with outcomes in these three categories across a wide variety of occupations.

- Burnout has been found to be related to negative work attitudes, job dissatisfaction. Lower levels of organizational commitment, higher levels of job stress, absenteeism and absence from work, and lower levels of job performance.

- Burnout has been shown to be related to higher levels of depression, chronic fatigue, psychosomatic symptoms, and a less satisfying home and personal life.

- Burnout has been found to predict negative reactions to organizational change, being disciplined for or job performance, and lower self-ratings of job performance.

Building on both previous nursing research and the broader research literature on the consequences of burnout, it was hypothesized that nurses reporting higher levels of burnout would report less favorable work outcomes, less nursing-specific satisfaction, diminished psychological health, and more negative perceptions of hospital functioning.

\section{Methods}

Procedure

This study was carried out in research hospitals in Ankara Turkey, research sites being randomly selected from the 15 research hospitals in that city. The Health Ministry sent a cover letter to the Chief Physicians of these hospitals requesting their cooperation. Six hundred questionnaires were administered to staff nurses in the hospitals. Measures originally in English were translated into Turkish using the back translation method. Data were collected in March 2009. Two hundred and seventeen nurses anonymously completed the surveys, a $36 \%$ response rate.

\section{Respondents}

Table 1 presents the personal demographic and work situation characteristics of the sample $(n=224)$. There was considerable diversity on each item. The sample ages ranged from under 325 to over 46, with 128 between 26 and 35 (60\%). Most were married (77\%), had children (70\%), worked full-time (79\%), wanted to work full-time 
(99\%), were female (88\%), worked between 41-45 hours per week (43\%), had a high school or vocational college education ( $58 \%$ ), did not have supervisory responsibilities (68\%), had not changed units in the past year $(74 \%)$, had five years or less of nursing tenure (59\%), five years or less of hospital tenure (57\%), and worked in a variety of nursing units.

Table 1. Demographic Characteristics of Sample

\begin{tabular}{|c|c|c|c|c|c|}
\hline Age & $\underline{N}$ & $\underline{\%}$ & $\underline{\text { Sex }}$ & $\underline{N}$ & $\underline{\%}$ \\
\hline 25 or less & $\overline{18}$ & 8.4 & $\overline{\text { Female }}$ & $18 \overline{0}$ & $87 . \overline{8}$ \\
\hline $26-30$ & 76 & 35.3 & Male & 25 & 12.2 \\
\hline $31-35$ & 52 & 24.4 & & & \\
\hline $36-45$ & 44 & 21.5 & Marital Status & & \\
\hline $41-45$ & 17 & 8.3 & Married & 168 & 77.4 \\
\hline 46 or older & 8 & 3.9 & Single & 49 & 22.6 \\
\hline Parental Status & & & Number of Children & & \\
\hline Children & 151 & 70.3 & 1 & 70 & 46.4 \\
\hline \multirow{2}{*}{ Childless } & 64 & 29.7 & 2 & 76 & 50.3 \\
\hline & & & 3 or more & 5 & 3.3 \\
\hline \multicolumn{6}{|l|}{ Education } \\
\hline High School & 75 & 34.6 & Work status & & \\
\hline Vocational School & 50 & 23.0 & $\overline{\text { Full-time }}$ & 160 & 79.4 \\
\hline Bachelor's degree & 70 & 32.2 & Part-time & 54 & 20.6 \\
\hline Master's degree & 2 & .9 & & & \\
\hline \multirow[t]{3}{*}{ Faculty } & 20 & 9.2 & Supervisory Duties & & \\
\hline & & & Yes & 69 & 31.8 \\
\hline & & & No & 148 & 68.2 \\
\hline \multicolumn{6}{|l|}{ Hours worked } \\
\hline 40 or less & 39 & 19.8 & Preferred Work status & & \\
\hline $41-45$ & 84 & 42.6 & Full-time & 197 & 99.5 \\
\hline $46-50$ & 38 & 18.3 & Part-time & 1 & .5 \\
\hline $51-55$ & 9 & 4.6 & & & \\
\hline \multirow[t]{2}{*}{56 or more } & 27 & 13.7 & Hospital Tenure & & \\
\hline & & & 5 years or less & 118 & 57.6 \\
\hline Changed Units Past Year & & & $6-10$ years & 49 & 23.9 \\
\hline Yes & & 26.0 & $11-15$ years & 14 & 6.8 \\
\hline \multirow[t]{2}{*}{ No } & 53 & 74.0 & $16-20$ years & 15 & 7.3 \\
\hline & 151 & & 21 years or more & 9 & 4.4 \\
\hline \multicolumn{6}{|l|}{ Nursing Tenure } \\
\hline 5 years or less & 119 & 59.1 & & & \\
\hline $6-10$ years & 41 & 20.4 & & & \\
\hline $11-15$ years & 14 & 7.0 & & & \\
\hline $16-20$ years & 18 & 9.0 & & & \\
\hline 21 years or more & 9 & 4.5 & & & \\
\hline
\end{tabular}


Measures

Personal and work situation characteristics

These were measured by single items (e.g., age, sex, level of education, unit tenure, hospital tenure).

\section{Burnout}

Three dimensions of burnout were measured by the Maslach Burnout Inventory (Maslach, Jackson \& Leiter, 1996). Respondents indicated how often they experienced each item on a seven-point scale $10=$ never, $3=$ a few times a month, $6=$ every day).

Exhaustion was measured by a five-item scale $(\alpha=.86)$. One item was "I feel burned out from my work."

Cynicism was assessed by a five-item scale $(\alpha=.58)$. An item was "I have become more cynical about whether my work contributes anything."

Efficacy was measured by six items $(\alpha=.77)$. One item was "I have accomplished many worthwhile things in this job."

\section{Work Outcomes}

Six work outcomes were included.

Job satisfaction was measured by a five-item scale $(\alpha=.79)$ developed by Quinn and Shepard (1974). One item was, "All in all, how satisfied would you say you are with your job?" Respondents indicated their responses on a four-point Likert scale (1-Very satisfied, 4=Not at all satisfied).

Absenteeism. Nurses indicated first how many days they had been absent from work during the past month, and then how many of these days of absenteeism were due to sickness.

Intent to quit ( $\alpha=.76$ ) was measured by two items used previously by Burke (1991). An item was, "Are you currently looking for a different job in a different organization?"

\section{Work engagement}

Three dimensions of work engagement were assessed using scales developed by Schaufeli et al. (2002) and Schaufeli and Bakker (2004). Respondents indicated their agreement with each item on a five-point Likert scale $11=$ Strongly disagree, $3=$ Neither agree nor disagree, 5= Strongly agree). 
Vigor was measured by six items ( $\alpha=$.82) An item was "At my work, I feel bursting with energy."

Dedication was measured by five items $(\alpha=.79)$. One item was "I am proud of the work that I do."

Absorption was assessed by six items $(\alpha=.85)$. An item was "I am immersed in my work."

\section{Psychological Well-being}

Five aspects of psychological well-being were included.

Positive Affect was measured by a ten-item scale $(\alpha=.91)$ developed by Watson, Clark and Tellegen (1988). Respondents indicated how often they experienced these items during the past week (e.g., excited, proud, excited) on a five-point Likert scale ( $1=$ not at all, 5=extreme).

Negative affect was also measured by a ten-item scale $(\alpha=.86)$ developed by Watson, Clark and Tellegen (1988). Respondents indicated how often they experienced these (e.g., irritable, nervous, distressed) on the same frequency scale.

Psychosomatic symptoms was measured by nineteen items $(\alpha=.91)$ developed by Quinn and Shepard (1974). Respondents indicated how often they had experienced each physical condition (e.g., headaches, having trouble getting to sleep) during the past year. Responses were made on a seven-point Likert scale (1=never, 4=often).

Medication use was measured by a five-item scale $(\alpha=.75)$ developed by Quinn and Shepard (1974). Respondents indicated how often they took listed medications (e.g., pain medication, sleeping pills) on a five point scale ( $1=$ never, $5=$ a lot).

Life satisfaction was assessed by a five-point scale $(\alpha=.90)$ developed by Quinn and Shepard (1974). Respondents indicated their agreement with each item (e.g., In most ways my life is close to ideal) on a seven-point Likert agreement scale ( l=Strongly agree, 4=neither agree not disagree, $7=$ Strongly disagree).

Perceptions of Hospital Functioning and Health Care

Four measures were included here, three assessing perceptions of hospital functioning, one assessing perceptions of patient care quality.

Health and Safety Climate

Nurses indicated their agreement with eight items $(\alpha=.64)$ based on items from Zohar and Luria (2005) and on an extensive review of the accident and safety climate literature. . An item was, "I feel free to report safety problems where I work." 
Again a five point Likert scale anchored by Strongly agree (5) and Strongly disagree (1) was used.

Workplace Errors and Accidents

Nurses indicated how frequently they observed six hospital incidents $(\alpha=. .64)$ on a four-point scale (1=never, 4=frequently). Incidents included, "Patient received wrong medication or dose," "patient falls with injuries"). This scale was created by the researchers,

Hospital Support

Hospital support was assessed by eight items $(\alpha=.95)$ developed by Eisenberger, Huntington, Hutchison and Sowa (1986). An item was, "This hospital is willing to help me when I need a special favor." Respondents indicated their agreement with each item on a seven-point Likert scale ( 1 = Strongly agree, $4=$ Neither agree nor disagree, $7=$ Strongly disagree).

Patient care

Nurses indicated on a single item their views on the quality of patient care provided ("In general, how would you describe the quality of nursing care delivered to patients on your unit?" (1=excellent, 4=poor)). This item was created by the researchers. Single items have been found to be highly reliable (Wanous \& Hudy, 2001)

Results

Inter-correlations among burnout measures

Only one of the three correlations among the burnout components was statistically significant: exhaustion was positively correlated with cynicism ( $r-.49, p<.001)$, Exhaustion and efficacy, and cynicism and efficacy, were both correlated .02 (ns), the sample sizes being 219 and 220 in these analyses.

Inter-correlations among outcome measures

Let us now consider the inter-correlations among the outcome measures within each of the three categories. First, inter-correlations among the six work outcomes ranged from a high of .62 to a low of .02 (the three work engagement measures were intercorrelated above .55, consistent $\dagger$ with previous research findings), with a mean correlation of .28. Second, inter-correlations among the five measures of psychological well-being ranged from a high of .38 to a low of .04 , with mean correlation of .21. Third, inter-correlations among the four indicators of hospital functioning ranged fro a high of .30 to a low of .20 , with a mean correlation of .18. 
Thus, with the exception of the inter-correlations among the three work engagement measurers, most correlations were relatively modest in size .In addition, correlations across the three categories were also generally modest in size indicating that the criterion variables were relatively independent.

Levels of burnout

The mean values on the three burnout components were as follows: exhaustion, 3.2 , cynicism, 2.8, and efficacy, 4.8. Thus this nursing sample had relatively low levels of exhaustion and cynicism but higher levels of efficacy. This sample tended to have slightly lower levels of exhaustion, slightly higher levels of cynicism and slightly lower levels of efficacy than other nursing samples.

Hierarchical Regression analysis

Hierarchical regression analyses were undertaken in which various work outcomes, indicators of psychological well-being and perceptions of hospital functioning were regressed on three blocks of predictors entered in a specified order. The first block of predictors $(n=4)$ consisted of personal demographics (e.g., age, marital status, level of education); the second block $(n=4)$ consisted of work situation characteristics (e.g., job has supervisory duties, hospital tenure, work status, full-time versus parttime); the third block of predictors $(n=3)$ consisted of the burnout components. When a block of predictors accounted for a significant amount or increment in explained variance $(p<.05)$, individual variables within these blocks having significant and independent relationships with the criterion variable $(p<.05)$ were identified. These variables are indicated in the tables that follow along with their respective $\beta$ s.

Predictors of Burnout

The three burnout components were separately regressed on two blocks of predictors: personal demographics and work situation characteristics. The two blocks of predictors accounted for a significant amount and increment in explained variance on exhaustion but no individual item had a significant and independent relationship with levels of exhaustion. Neither of the blocks of predictors accounted for a significant amount or increment in explained variance on levels of cynicism. of lack of efficacy. Thus neither personal demographics nor work situation characteristics had significant and independent relationships with any of the three burnout measures. 


\section{Burnout and Work Outcomes}

Table 2 presents the results of hierarchical regression analyses in which six work outcomes were regressed separately on the three blocks of predictors: personal demographics, work situation characteristics, and burnout. The following comments are offered in summary. First, burnout components accounted for a significant increment in explained variance in five of the six analyses (not for absenteeism). Nurses indicating higher levels of exhaustion also reported less job satisfaction, and lower levels of vigor and absorption (Bs=-.32, -.27 and -.18 , respectively). Nurses indicating higher levels of cynicism also indicated lower levels of job satisfaction, greater intentions to quit, and lower levels of both vigor and dedication (Bs=-.20, .24, -.22 and -.24, respectively) Finally, nurses indicting higher levels of efficacy also reported higher levels of vigor and absorption (Bs=.22 and .20, respectively).

Table 2: Burnout and Work Outcomes

\begin{tabular}{|c|c|c|c|c|}
\hline Job Satisfaction $(N=163)$ & $\underline{R}$ & $\underline{\mathrm{R}^{2}}$ & $\underline{\Delta R^{2}}$ & $\underline{P}$ \\
\hline Personal demographics & .23 & .05 & .05 & NS \\
\hline Work situation & .34 & .11 & .06 & NS \\
\hline Burnout & .56 & .32 & .21 & .001 \\
\hline \multicolumn{5}{|l|}{ Exhaustion (-.32) } \\
\hline \multicolumn{5}{|l|}{ Cynicism $(-.20)$} \\
\hline \multicolumn{5}{|l|}{ Intent to Quit ( $N=163)$} \\
\hline Personal demographics & .37 & .14 & .14 & .001 \\
\hline \multicolumn{5}{|l|}{ Marital status (-.22) } \\
\hline Work situation & .42 & .18 & .14 & NS \\
\hline Burnout & .52 & .27 & .09 & .001 \\
\hline \multicolumn{5}{|l|}{ Cynicism (.24) } \\
\hline \multicolumn{5}{|l|}{ Days Absent ( $N=163)$} \\
\hline Personal demographics & .09 & .01 & .01 & NS \\
\hline Work situation & .13 & .02 & .01 & NS \\
\hline Burnout & .24 & .04 & .02 & NS \\
\hline \multicolumn{5}{|l|}{ Engagement } \\
\hline \multicolumn{5}{|l|}{ Vigor $(N=165)$} \\
\hline Personal demographics & .27 & .08 & .08 & .05 \\
\hline Work situation & .42 & .18 & .10 & .01 \\
\hline \multicolumn{5}{|l|}{ Changed units (-.14) } \\
\hline Burnout & .63 & .39 & .21 & .001 \\
\hline \multicolumn{5}{|l|}{ Exhaustion (-.27) } \\
\hline Efficacy (.22) & & & & \\
\hline
\end{tabular}




\begin{tabular}{|c|c|c|c|c|}
\hline Cynicism (-.22) & & & & \\
\hline \multicolumn{5}{|l|}{ Dedication ( $N=163$ ) } \\
\hline Personal demographics & .14 & .02 & .02 & NS \\
\hline Work situation & .35 & .12 & .10 & .05 \\
\hline \multicolumn{5}{|l|}{ Work status (.23) } \\
\hline Burnout & .57 & .33 & .21 & .001 \\
\hline \multicolumn{5}{|l|}{ Efficacy (.33) } \\
\hline \multicolumn{5}{|l|}{ Cynicism (-.24) } \\
\hline \multicolumn{5}{|l|}{ Absorption ( $N=164)$} \\
\hline Personal demographics & .16 & 02 & .02 & NS \\
\hline Work situation & .36 & .13 & .11 & .05 \\
\hline \multicolumn{5}{|l|}{ Unit tenure $(-.36)$} \\
\hline Burnout & .49 & .24 & .11 & .01 \\
\hline \multicolumn{5}{|l|}{ Efficacy $(.20)$} \\
\hline Exhaustion (-.18) & & & & \\
\hline
\end{tabular}

Workload and Psychological Well-Being

Table 3 shows the results of hierarchical regression analyses involving five indicators of psychological well-being: positive and negative affect, psychosomatic symptoms, medication use and life satisfaction. The following comments are offered in summary. First, burnout measures accounted for a significant increment in explained variance in all five analyses. Nurses reporting higher levels of cynicism also indicated more psychosomatic symptoms, more medication use and less life satisfaction $(\mathrm{Bs}=.19, .21$ and -.18 , respectively); nurses scoring higher on exhaustion also indicated lower levels of Positive affect, less life satisfaction, and more psychosomatic symptoms (Bs=-.18, .39 and -.33, respectively). Finally, nurses indicating higher levels of efficacy also reported more positive affect and less negative affect (Bs=.27 and .20 , respectively).

Table 3: Burnout and Psychological Well-Being

\begin{tabular}{lllll}
\hline Psychological Well-Being & $\underline{R}$ & $\underline{R^{2}}$ & $\underline{\Delta R^{2}}$ & $\underline{P}$ \\
Positive Affect (N=161) & & & & \\
Personal demographics & .13 & .02 & .02 & $N S$ \\
Work situation & .25 & .06 & .04 & $N S$ \\
Burnout & .46 & .21 & .15 & .001 \\
$\quad$ Efficacy (.27) & & & & \\
$\quad$ Exhaustion (-.18) & & & &
\end{tabular}




\begin{tabular}{|c|c|c|c|c|}
\hline \multicolumn{5}{|l|}{ Negative Affect $(N=160)$} \\
\hline Personal demographics & .16 & .03 & .03 & NS \\
\hline Work situation & .27 & .07 & .04 & NS \\
\hline Burnout & .40 & .16 & .09 & .001 \\
\hline \multicolumn{5}{|l|}{ Efficacy $(-.20)$} \\
\hline \multicolumn{5}{|c|}{ Psychosomatic Symptoms ( $N=165)$} \\
\hline Personal demographics & .22 & .05 & .05 & NS \\
\hline Work situation & .29 & .08 & .03 & NS \\
\hline Burnout & .56 & .32 & .24 & .001 \\
\hline \multicolumn{5}{|l|}{ Exhaustion (.39) } \\
\hline \multicolumn{5}{|l|}{ Cynicism (.19) } \\
\hline \multicolumn{5}{|l|}{ Medication Use (N=162) } \\
\hline Personal demographics & .06 & .00 & .00 & NS \\
\hline Work situation & .19 & .04 & .04 & NS \\
\hline Burnout & .31 & .09 & .05 & .05 \\
\hline \multicolumn{5}{|l|}{ Cynicism (.21) } \\
\hline \multicolumn{5}{|l|}{ Life satisfaction ( $N=163)$} \\
\hline Personal demographics & .14 & .02 & .02 & NS \\
\hline Work situation & .21 & .04 & .02 & NS \\
\hline Burnout & .48 & .23 & .19 & .001 \\
\hline \multicolumn{5}{|l|}{ Exhaustion (.33) } \\
\hline Cynicism (.18) & & & & \\
\hline
\end{tabular}

Workload and Perceptions of Hospital Functioning and Patient Care

Table 4 presents the results of hierarchical regression analyses in which four indicators of perceived hospital functioning and quality of patient care were regressed on the three blocks of predictors. The burnout measures accounted for a significant increment in explained variance in all four analyses. Nurses scoring higher on cynicism also reported a less favorable health and safety climate, lower levels of hospital support, more hospital incidents of errors and accidents and more negative perceptions of the quality of patient care (Bs=-.18, , -.23..26, and -.21, respectively). Nurses scoring higher on exhaustion also indicated lower levels of hospital support $(B=.-.17)$. 
Table 4: Burnout, Hospital Functioning and Nursing Satisfaction Hospital Functioning

\begin{tabular}{|c|c|c|c|c|}
\hline Health and Safety & $\underline{R}$ & $\underline{R^{2}}$ & $\Delta \mathrm{R}^{2}$ & $\underline{P}$ \\
\hline \multicolumn{5}{|l|}{ Climate $(N=164)$} \\
\hline Personal demographics & .17 & .03 & .03 & NS \\
\hline Work situation & .30 & .09 & .03 & NS \\
\hline Burnout & .39 & .15 & .06 & .05 \\
\hline \multicolumn{5}{|l|}{ Cynicism $(-.18)$} \\
\hline \multicolumn{5}{|l|}{ Hospital Support ( $N=162$ ) } \\
\hline Personal demographics & .15 & .03 & .03 & NS \\
\hline Work situation & .24 & .06 & .03 & NS \\
\hline Burnout & .42 & .20 & .14 & .001 \\
\hline \multicolumn{5}{|l|}{ Cynicism (-.23) } \\
\hline \multicolumn{5}{|l|}{ Exhaustion (-.17) } \\
\hline \multicolumn{5}{|c|}{ Hospital Errors and Accidents ( $N=161)$} \\
\hline Personal demographics & .13 & .02 & .02 & NS \\
\hline Work situation & .17 & .03 & .01 & NS \\
\hline Burnout & .33 & .11 & .08 & .001 \\
\hline \multicolumn{5}{|l|}{ Cynicism (.26) } \\
\hline \multicolumn{5}{|c|}{ Quality of Patient Care ( $N=164)$} \\
\hline Personal demographics & .23 & .06 & .06 & NS \\
\hline Work situation & .25 & .06 & .00 & NS \\
\hline Burnout & .37 & .14 & .08 & .01 \\
\hline Cynicism (-.21) & & & & \\
\hline
\end{tabular}

\section{Discussion}

This study provided preliminary support for the general hypothesis underlying the research That is, nursing staff indicting higher levels of burnout also reported less favorable work outcomes, poorer psychological well-being, and perceived their hospital functioning at a less support, less safe and providing a lower patient care quality. These findings were generally consistent with previously reported nursing research carried out in North America so these findings were generalized to nurses in Turkish hospitals. In addition, the findings were consistent with those found in various occupation, in different countries, and including additional outcome measures. Interestingly, the nurses in our sample indicated lower levels of burnout than did nurses in other investigations but the pattern of findings was the same. 
Practical implications

The notion of burnout has both research and practice relevance. Some writers have offered suggestions for reducing levels of burnout in the workplace (e.g., Burke \& Richardsen, 2001; Schaufeli \& Buunk, 2003). Researchers have suggested interventions at both individual and organizational levels, and the fit between the two, with most efforts being directed at the individual level. Individual level interventions include cognitive behavioral techniques such as stress inoculation, rational emotive approaches, cognitive restructuring. behavioral rehearsal, relaxation techniques, and training programs to reduce reality shock, work-family conflict, and employee passivity and increase coping skills. Workplace interventions include work redesign to reduce workload, attempts to increase levels of social support at work, increase levels of employee participation in decision making, and offering career counseling to support employee development..

The results of this study among nurses showed that burnout influenced work attitudes, psychological health, and perceptions of hospital functioning. Leiter (2006) observed that relationships with one's work reflect investments from both individuals and their work environments. He proposed various targets for decreasing levels of burnout by addressing six areas of worklife: workload, control, rewards, community, fairness, and values to increase the fit between individual needs and organizational work experiences.. Mismatch between individuals and their workplaces in any of these areas in creases burnout. Leiter and Maslach (2005) offer guidance on ways of addressing mismatches in these six areas, as well as problem diagnosis and processes for generating solutions and taking action. Some examples include the following:

- Workload -redesign work so it better fits both organizational and individual needs (e.g., more innovative work, focusing on high priority tasks)

- Control - increasing influence and participation in decision making

- Rewards - more recognition, more supportive interactions with one's supervisors.

- Community - increasing interactions with one's colleagues, ore use of teams

- Fairness - strengthen mutual respect, equal treatment of employees, more open and transparent procedures and policies

- Valves - highlight organizational values, articulate these, act in accordance with espoused values, orient new employees to the organization's values

There have been two approaches to reducing burnout in the workplace, one tries to change individual employees while the other tries to change the environment of 
organizations (Leiter \& Maslach, 2005).Both likely have value, but changing organizational workplaces probably has greater benefits for more employees. Some have suggested an ongoing collaborative action research program to target burnout (Halbesleben, Osburn \& Mumford, 2006). By identifying a variety of problems and opportunities through surveys and in focus groups, these can be used as the basis for developing and implementing a formal organizational plan. However, they conclude that $\mathrm{n}$ order to be successful, organizations need to continuously re-cycle through this process to increase organizational learning and problem solving skills.

Schaufeli and Salanova (2007) discuss how organizational strategies such as personnel assessment and evaluation, job redesign, leadership and training can be used to decrease burnout. Employee assessment and evaluation supports the development of a psychological contract that improves the fit of the employee and organization. Job redesign both reduces employee health-related risks and increases employee motivation, and leadership builds the emotional climate of the organization increasing motivation. Interventions such as wellness audits and workshops that promote employee health and well-being, training and career development to foster support for continuous employee growth, will increase the quality of work. Thus reducing demands and increasing resources may have success with nurses in terms of reducing strain and burnout.

Limitations of the research

Some limitations of the research should be noted to put the findings into a broader context. The sample of nurses in this study was small $(n=224)$. It was not possible to determine the representativeness of those nurses that participated. All data were collected using self-report questionnaires raising the possibility of response set tendencies. The data were collected at one point in time making it difficult to determine causality. All respondents worked in research hospitals. It is not clear the extent to which our results would generalize to other samples of nurses working in other hospitals In addition, a few of the measures had levels of internal consistency reliability slightly below the generally accepted level of .70.

Future research directions

Future research needs to involve a larger and representative sample of nurses drawn from several different hospitals. And including, for example, indicators of psychological well-being as predictors of work outcomes, in addition to using the three $\mathrm{MBI}$ scales, would indicate which of these two groups of predictors accounts 
for more variance on work outcomes. Our understanding of the antecedents and consequences of burnout would also be increased through the use of longitudinal research designs. In addition, given our increasing understanding of the causes of burnout, an evaluation of workplace interventions targeted at reducing levels of burnout seems warranted (Rundall, Starkweather \& Norrish, 1998).

\section{References}

Aiken, L. H., Clarke, S. P., Sloane, D. M., \& Sochalski, J. (2001). Nurses' reports on hospital care in five countries. Health Affairs, 20, 343-353.

Aiken, L. H., Clarke, s. P., Sloane, D. M., Sochalski, J., \& Silber, J. H. (2002). Hospital nurse staffing and patient mortality, nurse burnout and job dissatisfaction. Journal of the American Medical Association, 288, 1987-1993.

Bakker, A. B. (2008). Building engagement in the workplace. In R. J. Burke \& C. L. Cooper (eds.) The peak performing organization. London: Routledge pp. 50-72.

Bakker, A.B.,. LeBlanc, P. M., \& Schaufeli, W. B. (2003). Burnout contagion among intensive care nurses. Journal of Advance Nursing, 51, 276-287.

Bakker, A. B., Killmer, C. H., Seigrist, J., \& Schaufeli, W.B. (2000). Effort-reward imbalance and burnout among nurses. Journal of Advanced Nursing, 31, 884-891.

Burke, R. J. (1991). Early work and career experiences of female and male managers: Reasons for optimism? Canadian Journal of Administrative Sciences, 8, 224-230.

Burke, r. J., \& Richardsen, A. M. (2001). Psychological burnout in organizations: Research and intervention. IN R. T. Golembiewski (ed.) Handbook of organizational behavior. New York: Marcel Dekker, Inc. pp. 327-364.

Chen, S. M., \& McMurray, A. (2001). "Burnout" in intensive care nurses. Journal of Nursing Research, 9, 152-164.

Davy, C. (2007). Contributing to the wellbeing of primary health care workers in PNG. Journal of Health Organization and Management, 21, 229-245.

Eisenberger, R., Huntington, R., Hutchison, S. H., \& Sowa, D. (1986). Perceived organizational support. Journal of Applied Psychology, 71, 500-507. 
Greenglass, E. R., Burke, R. J., \& Fiksenbaum, L. (2001). Workload and burnout in nurses. Journal of Community and Applied Social Psychology, 11, 211-215.

Halbesleben, J. R.B., Osburn, H. K., \& Mumford, M. D. (2006). Action research as a burnout intervention: Reducing burnout in the Federal Fire Services. Journal of Applied Behavioral Science, 42, 244-266.

Laschinger, H. K., Finegan, J., Shamian, J., \& Wilk, P. (2003). Workplace empowerment as a predictor of nuse burnout in restructured healthcare settings. Longwoods Review, 1, 211.

Leiter, M. P., \& Maslach, C. (2009). Nurse turnover: The mediating role of burnout. Journal of Nursing Management, 17, 331-339.

Leiter, M. P. (2006). Engagement with work: Issues for measurement and intervention. In R. J. Burke \& C. L. Cooper (eds.) The human resources revolution: Why putting people first matters. London: Elsevier. pp. 213-230.

Leiter, M. P., \& Maslach, C. (2005). A mediation model of job burnout. In Antoniou, A-S G., \& Cooper, C. L. (eds.) Research companion to organizational health psychology, Cheltenham, UK: Edward Elgar. pp. 544-564.

Leiter, M. P., \& Maslach, C. (2005) Banishing burnout. San Francisco: Jossey-Bass.

Maslach, C. \& Leiter, M. P. (1997) The truth about burnout. San Francisco: Jossey-Bass.

Maslach, C. \& Jackson, S. E. (1986) The Maslach Burnout Inventory. Manual (2nd ed.) Palo alto, CA: Consulting Psychologists Press.

Maslach, C. \& Jackson, S. E,. (1981) The measurement of experienced burnout. Journal of Organizational Behavior, 2, 99-113.

Maslach, C., Leiter, M. P. \& Schaufeli, W. (2009) Measuring burnout.In S. Cartwright \& C. L. Cooper (eds.) The Oxford handbook of organizational well-being. Oxford: Oxford Univerrsity Press. pp. 86-108.

Maslach, C., Jackson, S. E., \& Leiter, M. P. (1996). The Maslach Burnout Inventory (3rd ed.). Palo Alto, CA: Consulting Psychologists Press. 
Papadatou, D., Asagnostopoulos, fF, \& Monos, D. (1994) Factors contributing to the development of burnout in oncology nursing. British Journal of Medical Psychology, 67, 187-199.

Poncet, M. C., Toullic, P., Papazian, L., Kientish-Barnes, N., Timsit, J.-F., Pochard, F., Chevret, S. Schlemmer, B., \& Azoulay, E. (200) Burnout syndrome in critical care nursing staff. American Journal of Respiratory and Critical Care Medicine, 175, 698-704.

Quinn, R. P., \& Shepard, L. J. (1974). The 1972-73 Quality of Employment Survey. Ann Arbor, Ml: Institute for Social Research, University of Michigan.

Rundall, T., Starkweather, D. B., \& Norrish, B. R. (1998) After restructuring: Empowerment strategies at work in America's hospitals. San Francisco: Jossey-Bass.

Schaufeli, W. B., \& Salalnova, M. (2007) Work engagement: An emerging psychological concept and its implications for organizations. In S.W. Gilliland, D. D. Steiner \& D. P. Skarlicki (eds.) Research in social issues in management (Volume 5). Greenwich CT: Information Age Publishers. pp. 135-177.

Schaufeli, W. B., \& Bakker, A. B. (2004). Job demands, job resources and their relationship with burnout and engagement: A multi-sample study. Journal of Organizational Behavior, 25, 293-315.

Schaufeli, W. B., \& Buunk, B. P. (2003) Burnout: an overview of 25 years of research and theorizing. In M. J. Schabracq, J. A. M. Winnubst \& C. L. Cooper (eds.) The handbook of work and health psychology (2nd edition) New York: John Wiley. pp. 383-427.

Schaufeli, W. B., Leiter, M. P., \& Maslach, C. (2008) Burnout: 35 years of research and practice. Career Development International. 14, 204-220.

Schaufeli, W. B., Maslach, C., \& Marek, T. (1993) Professional burnout: Recent developments in theory and research. London. Taylor \& Francis.

Schaufeli, W. B., Salanova, M., Gonzalez-Roma, V., \& Bakker, A. B. (2002). The measurement of engagement and burnout: A confirmative analytic approach. Journal of Happiness Studies, 3, 71-92.

Shirom, A., \& Melamed, S. (2005). Does burnout affect physical health? A review of the evidence. In A-S. G. Antoniou \& C. L. Cooper (eds..) Research companion to organizational health psychology. Cheltenham, UK: Edward Elgar. pp. 599-622. 
Vahey, D. C, Aiken, L. H., Sloane, D. M., Clarke, S. P., \& Vargas, D. (2004). Nurse burnout and patient satisfaction. Medical Care, 42, 1157-1166.

Wanous, J. P., \& Hudy, M. (2001). Single-item reliability: A replication and extension. Organizational Research Methods, 4, 361-375

Watson, D., Clark, L. A., \& Tellegen, A. (1988). Development and validation of brief measures of positive and negative affect: The PANAS scales. Journal of Personality and Social Psychology, 54, 1063-1070.

Zohar, D., \& Luria, G. (2005). A multi-level model of safety climate: Cross-level relationships between organizations and group-level climates Journal of Applied Psychology, 90, 616-628.

\section{About the authors:}

Ronald J. Burke is currently Professor of Organizational behavior Schulich School of Business, York University. His research interests include corruption in organizations, occupational health and safety and corporate reputation.

E-mail: rburke@schulich.yorku.ca

Mustafa Koyuncu is Professor of Management, Faculty of Commerce and Tourism Education, Nevsehir University. His research interests include tourism education, human resource management in the tourism and hospitality sector, and cross cultural research in tourism.

Lisa Fiksenbaum is currently a PhD candidate in the Department of Psychology, York University. Her research interests include work and family. strress and health and statistical methods. 